\title{
Frontiers of stent-assisted aneurysm coiling
}

\author{
Boris Lubicz
}

Received: 28 August 2010 / Accepted: 28 September 2010/Published online: 6 October 2010

(C) Springer-Verlag 2010

Endovascular treatment (EVT) by selective coiling is nowadays considered as the first-intention treatment of intracranial aneurysms (IA); however, EVT presents two major limitations: (1) treatment of wide-necked aneurysms and (2) recanalization. In order to circumvent these limitations, many new devices have been developed over the last decade (bioactive coils, liquid embolic agent, supporting devices, etc.). Among them, intracranial stenting with dedicated self-expandable stents is clearly the most promising one.

Many authors have evaluated stent-assisted coiling showing that this technique was effective and safe for EVT of complex IA, including wide-necked and fusiform lesions [1-5]; however, it has also been shown that the use of the associated mandatory anticoagulation/antiplatelet medication may increase the complication rate when compared to conventional coiling [6]. This potentially higher complication rate is mostly seen in patients with ruptured IA. Therefore, most authors agree that stentassisted coiling may be proposed for patients with unruptured IA, whereas it must be strictly limited to otherwise untreatable ruptured IA [1-7]. Stenting has thus brought a satisfying answer to one of EVT's limitations by enlarging its indications.

On the other hand, the adjunctive effect of stenting on IA occlusion has been suggested for years in experimental and early clinical studies [1-5, 7-11]. Indeed, stents should be considered as mechanical, hemodynamical, and biological active devices that may help prevent aneurysm recanaliza-

\section{B. Lubicz ( $ه)$}

Department of Diagnostic and Interventional Neuroradiology, Erasme University Hospital,

Hôpital Erasme, 808 route de Lennik,

1070 Bruxelles, Belgium

e-mail: blubicz@ulb.ac.be tion and contribute to vessel wall healing. Few authors have recently reported the positive effect of stenting over the stability of aneurysm occlusion $[6,12,13]$; however, we must admit that only large randomized studies will allow us to draw final conclusions. Last but not least, in large series with midterm follow-up, the percentage of in-stent stenosis is low, around $5 \%$, in the vast majority without clinical symptoms [1-6, 12-14]. Stenting will thus probably bring an answer to EVT's second limitation by stabilizing its anatomical results.

For all these reasons, it appears obvious that the use of stents will continue to expand EVT indications. Recently, new "audacious" techniques using stents have been reported: X- and Y-stenting, the waffle-cone technique that consists of placing the distal end of a stent directly into the base of a bifurcation aneurysm and coiling through the expanded and cone-shaped distal stent end [15-18].

All authors agree that these "audacious" stent-assisted techniques should ideally be restricted to otherwise untreatable IA. Indeed, $\mathrm{X}$ - and Y-stenting require the use of multiple stents within very small vessels and one can seriously fear for long-term tolerance. Concerning the waffle-cone technique, the recurrence rate seems very high because the arterial flow is "focused" via the stent on the aneurysm base. That is the reason why authors recommend performing an early control to exclude any quick major recanalization. In daily practice, these techniques - and mostly the waffle-cone technique with its "disappointing" anatomical results - could easily be proposed as firstintention treatment for posterior circulation aneurysms whereas clipping might remain the first choice in the anterior circulation until long-term results are known. On the other hand, the permanent release of new, better, safer, etc. devices might make us sometimes forget this wise and cautious approach. 
We clearly see that frontiers of stent-assisted aneurysm coiling are not related to the technique itself. Thanks to the new available devices, all IA are theoretically treatable by endovascular approach. These frontiers are simply related to the definition of "otherwise untreatable" IA that may vary a lot among physicians and neurovascular teams. It highlights, once again, the need for a multidisciplinary neurointerventional-neurosurgical approach that aims to offer the best treatment (lower complication rate, stable anatomical results) to our patients. To be provocative, I would say that the ideal equilibrium is perhaps reached when the neurointerventionalists are suggesting clipping while vascular neurosurgeons are asking us to stent.

Conflict of interest statement I declare that I have no conflict of interest.

\section{References}

1. Biondi A, Janardhan V, Katz JM, Salvaggio K, Riina HA, Gobin YP (2007) Neuroform stent-assisted coil embolization of wideneck intracranial aneurysms: strategies in stent deployment and midterm follow-up. Neurosurgery 61:460-468

2. Lubicz B, Leclerc X, Levivier M, Brotchi J, Pruvo JP, Lejeune JP, Balériaux D (2006) Retractable self-expandable stent for endovascular treatment of wide-necked intracranial aneurysms: preliminary experience. Neurosurgery 58:451-457

3. Lubicz B, François O, Levivier M, Brotchi J, Balériaux D (2008) Preliminary experience with the enterprise stent for endovascular treatment of complex intracranial aneurysms: potential advantages and limiting characteristics. Neurosurgery 62:1063-1069

4. Wanke I, Forsting M (2008) Stents for intracranial wide-necked aneurysms: more than mechanical protection. Neuroradiology 50:991-998

5. Yavuz K, Geyik S, Pamuk AG, Koc O, Saatci I, Cekirge S (2007) Immediate and midterm follow-up results of using an electrodetachable, fully retrievable SOLO stent system in the endovascular coil occlusion of wide-necked cerebral aneurysms. J Neurosurg 107:49-55
6. Piotin M, Blanc R, Spelle L et al (2010) Stent-assisted coiling of intracranial aneurysms: clinical and angiographic results in 216 consecutive aneurysms. Stroke 41:110-115

7. Lubicz B, Collignon L, Lefranc F, Bruneau M, Brotchi J, Balériaux D, De Witte O (2008) Circumferential and fusiform intracranial aneurysms: reconstructive endovascular treatment with self-expandable stents. Neuroradiology 50:499-507

8. Hirabayashi M, Ohta M, Rüfenacht DA, Chopard B (2003) Characterization of flow reduction properties in an aneurysm due to a stent. Phys Rev E Stat Nonlin Soft Matter Phys 68(2 Pt 1):021918

9. Lieber BB, Gounis MJ (2002) The physics of endoluminal stenting in the treatment of cerebrovascular aneurysms. Neurol Res 24(Suppl 1):S33-S42

10. Barath K, Cassot F, Fasel JH, Ohta M, Rüfenacht DA (2005) Influence of stent properties on the alteration of cerebral intraaneurysmal haemodynamics: flow quantification in elastic sidewall aneurysm models. Neurol Res 27:S120-S128

11. Dorn F, Niedermeyer F, Balasso A, Liepsch D, Liebig T (2010) The effect of stents on intra-aneurysmal hemodynamics: in vitro evaluation of a pulsatile sidewall aneurysm using laser Doppler anemometry. Neuroradiology (in press)

12. Sedat J, Chau Y, Mondot L, Vargas J, Szapiro J, Lonjon M (2009) Endovascular occlusion of intracranial wide-necked aneurysms with stenting (Neuroform) and coiling: mid-term and long-term results. Neuroradiology 51:401-409

13. Lubicz B, Bandeira A, Bruneau M, Dewindt A, Balériaux D, De Witte $O$ (2009) Stenting is improving and stabilising anatomical results of coiled intracranial aneurysms. Neuroradiology 51:419-425

14. Fiorella D, Albuquerque FC, Woo H, Rasmussen PA, Masaryk TJ, Mc Dougall CG (2006) Neuroform in-stent stenosis: incidence, natural history, and treatment strategies. Neurosurgery 59:34-42

15. Chow MM, Woo HH, Masaryk TJ, Rasmussen PA (2004) A novel endovascular treatment of a wide-necked basilar apex aneurysm by using a Y-configuration, double-stent technique. AJNR Am J Neuroradiol 25(3):509-512

16. CM TWE, Woo HH, Masaryk TJ, Rasmussen PA (2005) Yconfigured dual intracranial stent-assisted coil emoblization for the treatment of widenecked basilar tip aneurysms. Neurosurgery $56: 1035-1040$

17. Horowitz M, Levy E, Sauvageau E, Genevro J, Guterman LR, Hanel R, Wehman C, Gupta R, Jovin T (2006) Intra/extraaneurysmal stent placement for management of complex and wide-necked- bifurcation aneurysms: eight cases using the waffle cone technique. Neurosurgery 58(4 Suppl 2):ONS-258-262

18. Sychra V, Klisch J, Werner M et al. (2010) Waffle-cone technique with Solitaire AB Remodeling Device: endovascular treatment of highly selected complex cerebral aneurysms. Neuroradiology (in press) 